\title{
PARAGOGE OF ROSES BLACKPINK'S CAPTIONS ON INSTAGRAM
}

\author{
1Meiyanti Nurchaerani, ${ }^{2} E n d a h$ Siti Bilkis, ${ }^{3 R i a}$ Nirwana \\ Universitas Esa Unggul, Universitas Putera Indonesia Cinjur, \\ Universitas Al Ghifari Bandung \\ meiyanti.nurchaerani@esaunggul.ac.id \\ sitibilkisendah@gmail.com \\ ria.nirwana2@gmail.com
}

\begin{abstract}
This analysis was conducted on searching and researching of adding letters at the end of the word. The addition of a letters in the end was known as Paragoge. This analysis focuses on Rose Blackpink Captions On Instagram. This analysis used a descriptive qualitative, According to the case the researcher will use the book of "The Mopophonemics of english" by Lam Nguyen Tai, book "Psycholinguistic a resource book for students" by John Filed.
\end{abstract}

Key words: Paragoge, Morpophonemic, Psycholinguistics.

\section{INTRODUCTION}

Paragoge is one of typological name that often occurs in linguistics. Paragoge is part of addition or insertion that is included in morphophonemics (study of the relationship between morphology and phonology) which is also relates to psycholinguistics. The word comes from Greek para, which means beyond, and goge, which means carrying. This term is generally applied to various kinds of vowel or consonant additions that are not true suffixes, but generally decorative additions meant to add emphasis, but that do not change the common meaning of the word.

\section{PREVIOUSE RESEARCH}

1. E-Ching Ng (2013). Paragoge as an indicator of languagae contact.

The research explain that paragoge as abudantly attested in second language.

\section{LITERATURE REVIEW}

Psycholinguistics is the study of the mental aspect of language and speech. it's primarily concerned with the ways in which language is represented and processed in the brain. According to Filed, John. " Psycholinguistics explores the relationship between the human mind and language. It treats the language user as an individual rather than a representative of society -but an 
individual whose linguistics performance is determined by the strengths and limitations of the mental apparatus which we all share"

Morphponemic is the study of the relationship between morphology and phonology, according to Lai, Lam Nguyem. "Morphophonemics, a branch of morphology, deals with the variation in the forms of morphemes because of phonetic factor."

In the morphpnemics there is a type one of them is addition, addition have three type there are: Prothesis, epenthesis and paragoge, in this research will be focused on the paragoge.

Paragage is the additionan letter in the end of word, according to Crowley, Terry. (1997) "paragoge is the addition of sound to the end of word. Often is due to nativization." And according to A. Leverkuhn " paragoge is the addition of a letter or syllable to the end of a word. The word comes from Greek para, which means beyond, and goge, which means carrying. This term is generally applied to various kinds of vowel or consonant additions that are not true suffixes, but generally decorative additions meant to add emphasis, but that do not change the common meaning of the word."

\section{RESEARCH QUESTION}

Based on the title above, the researcher would like to present research questions as follow:

1. What are the error writing found on Roses Blackpink's captions on instagram wich connected with paragoge?

2. What kind of changes or additional of vowel structure and consonant on error writing on Roses Blackpink's captions on instagram?

\section{METHODOLOGY}

In this research, the researcher use a descriptive qualitative research, because the researcher purposes to describe the paragoge on Rose BlackPink's captions on isntagram. According to Creswell (1998,p.20):

"Qualitative procedures stand in stark contrast to the methods of quantitative research. Qualitative inquiry employs different knowledge claims, strategies of inquiry, and methods of data collection and analysis. Although the processes are similar, qualitative procedures rely on text and image data, have unique steps in data analysis, and draw on diverse strategies of inquiry."

\section{ANALYSIS}

The researcher found any writing errors on Roses Blackpink's caption on 
instagram which connected with paragoge because she was added of vowel structure and consonant on error writing.

Sample 1:

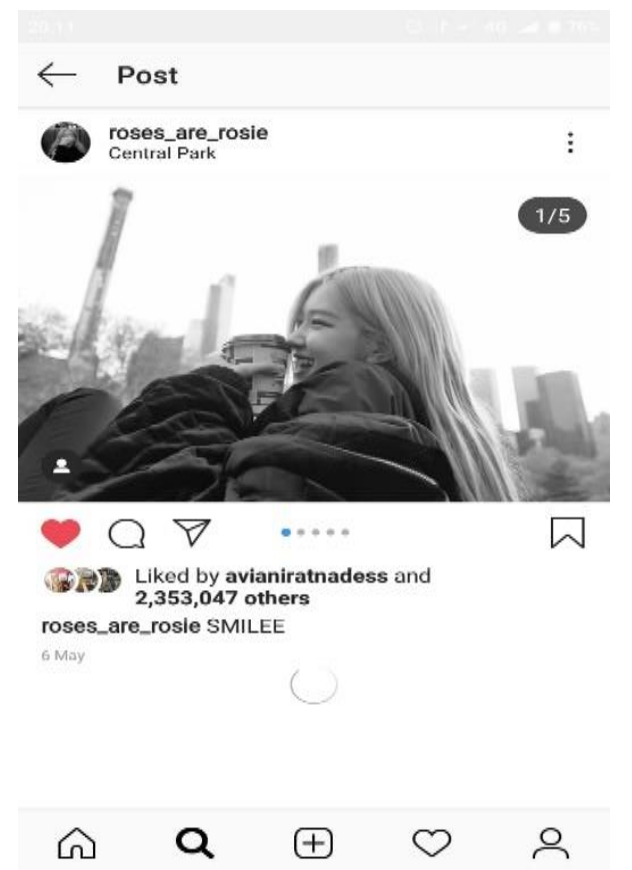

In sample 1 the data was taken on May 20, 2019 on Roses_are_rosie's statues posting on may 6, 2019. In a word 'SMILE' is written to 'SMILEE', the word 'SMILE' consist of five characters, they are S-M-I-L-E than Roses was
For the data the researcher will be discribe below:

\begin{tabular}{|l|l|}
\hline Smile & CCVCV \\
\hline Smilee & CCVCVV \\
\hline
\end{tabular}

written SMILEE, she was paragoged the word 'SMILE' by consonant ' $E^{\prime}$-> 'SMILEE' and it changed CV sequnce CCVCV became CCVCVV sequence of SMILEE. 
Sample 2:

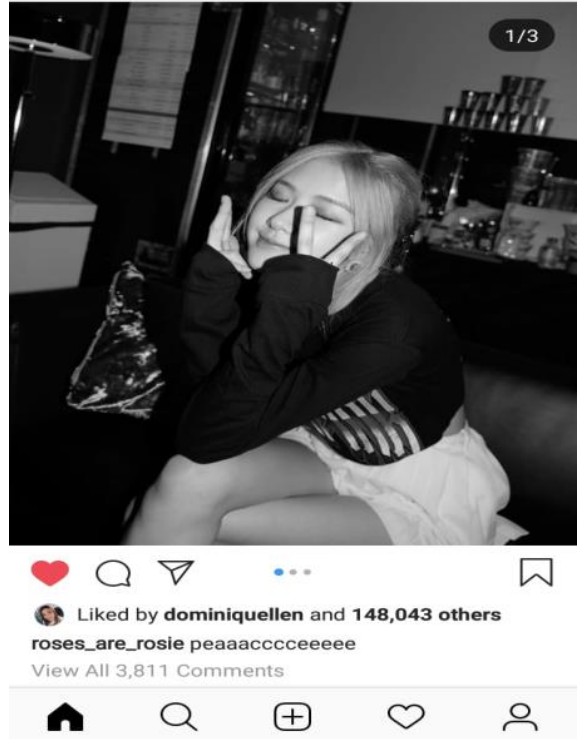

In sample 2 the data was taken on May 20, 2019 on Roses_are_rosie's statues posting on may 20, 2019. In a word 'PEACE' is written to 'PEAAACCCEEE', the word 'PEACE' consist of five characters, they are P-EA-C-E than Roses was written

\begin{tabular}{|l|l|}
\hline Peace & CVVCV \\
\hline Peaaaccceee & CVVVVCCCVVV \\
\hline
\end{tabular}

PEAAACEEE, she was paragoged the word 'PEACEE' by vowel 'AA' in the midle word and ' $E E$ ' in the end of the word $->$ 'PEAAACCCEEE' and it changed CVVCV sequence became CVVVVCCCVVV sequence of PEAAACCCEEE.

Sample 3:

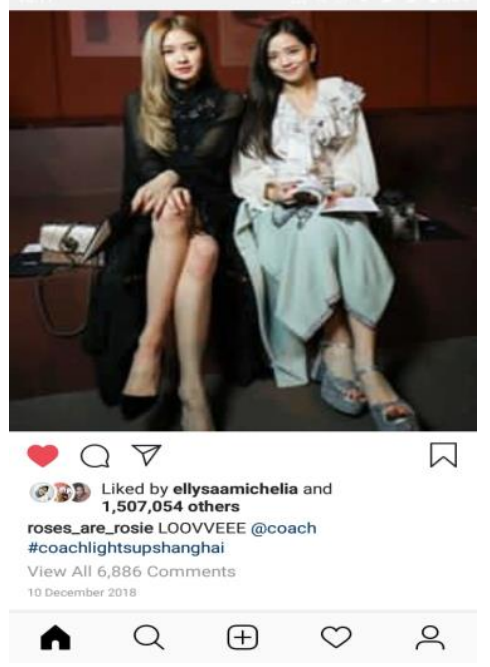

\begin{tabular}{|l|l|}
\hline Love & CVCV \\
\hline Loovee & CVVCVV \\
\hline
\end{tabular}


In sample 3 the data was taken on May 20, 2019 on Roses_are_rosie's statues posting on december10, 2018. In a word 'LOVE' is written to 'LOOVEE', the word 'LOVE' consist of four characters, they L-O-V-E than Roses was written

Sample 4:

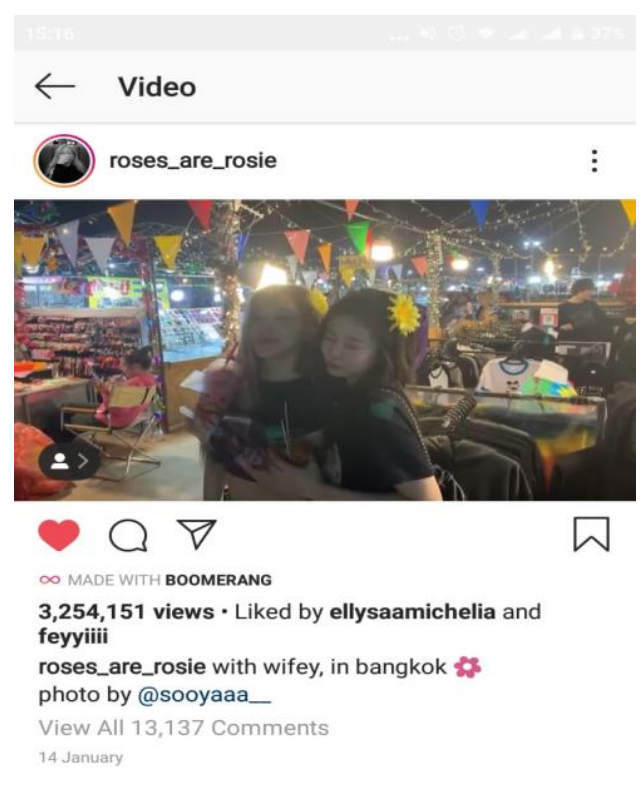

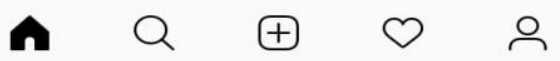

In sample 4 the data was taken on May 20, 2019 on Roses_are_rosie's statues posting on january 16, 2018. In a word 'WIFE' is written to WIFEY, the word 'WIFE' consist of four characters, they W-I-F-E than Roses was written WIFEY,
LOOVEE, she was paragoged the word 'LOOVEE' by vowel ' $\mathrm{O}$ ' in the midle word and ' $E$ ' in the end of the word -> 'LOOVEE' and it changed $\mathrm{CvCV}$ sequence became CVVCVV sequence of LOOVEE.

\begin{tabular}{|l|l|}
\hline wife & CVCV \\
\hline Wifey & CVCVC \\
\hline
\end{tabular}

she was paragoged the word 'WIFE' by consonant ' $Y$ ' in the end of the word -> 'WIFEY' and it changed $\mathrm{cvcv}$ sequence became CVCVC sequence of WIFEY. Then her captions tobe with wifey, in bangkook. 
Meiyanti Nurchaerani: Paragoge of...

Sample 5:

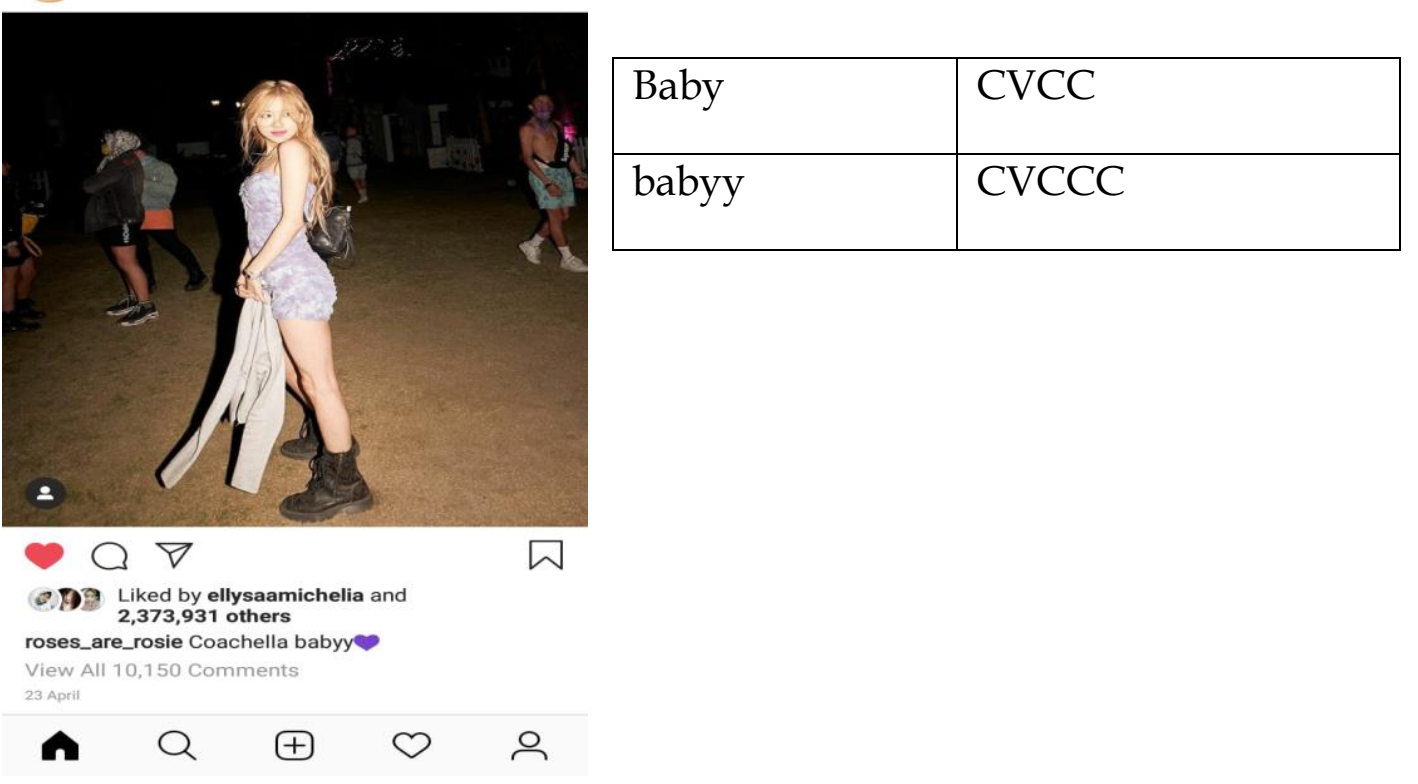

In sample 5 the data was taken on May 20, 2019 on Roses_are_rosie's statues posting on April 23, 2019. In a word ' $B A B Y$ ' is written to BABYY, the word 'BABY' consist of four characters, they B-A-B-Y than Roses was written
BABYY, she was paragoged the word 'BABY' by consonant ' $Y$ ' in the end of the word $\rightarrow>$ 'BABYY' and it changed CVCC sequence became CVCCC sequence of BABYY.

Sample 6:

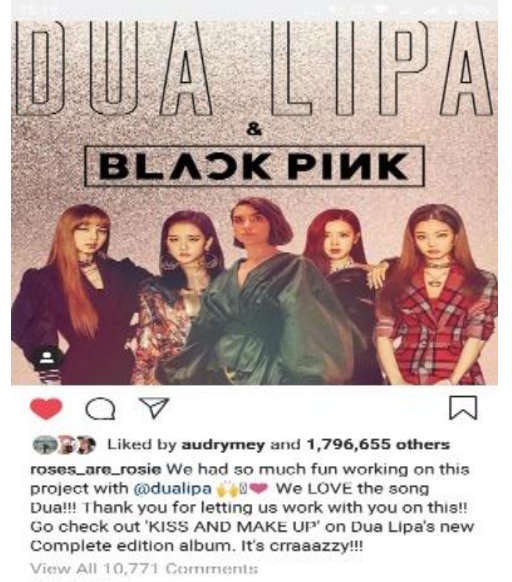

\begin{tabular}{|l|l|}
\hline Crazy & CCVCC \\
\hline crraaazzy & CCCVVVCCC \\
\hline
\end{tabular}

6 
In sample 6 the data was taken on May 20, 2019 on Roses_are_rosie's statues posting on october 26, 2018. In a word 'CRAZY' is written to CRRAAAZZY, the word 'CRAZY' consist of five characters, they C-R-A-Z-Y than Roses was written CRRAAAZZY, she was Sample 7:

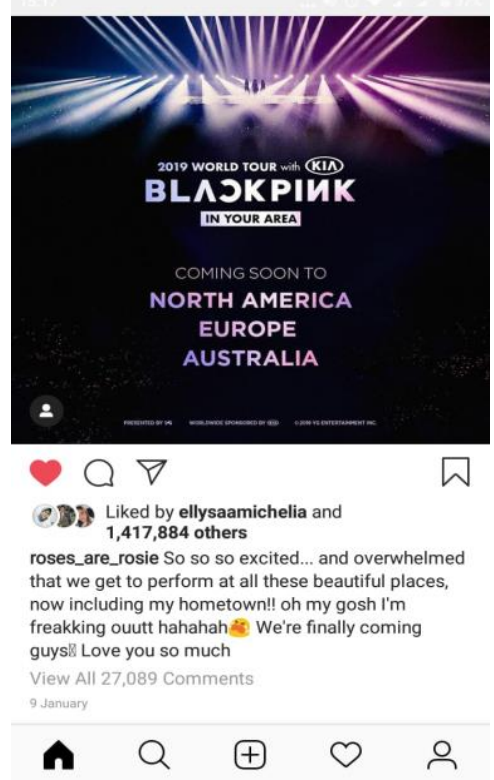

In sample7 the data was taken on May 20, 2019 on Roses_are_rosie's statues posting on january 9, 2019. In a word 'FREAK' is written to 'FREAKKING', the word 'FREAK' consist of five characters, they f-r-e-a-k than Roses was written FREAKKING, she was paragoged the word 'FREAK' by paragoged the word 'CRAZY by consonant ' $R$ ' in the third word added by vowel ' $A$ ' in the middle and consonant ' $Z$ 'before the last word -> CRRAAAZZY' and it changed CCVCC sequence became CCCVVVCCC sequence of CRRAAAZZY.

\begin{tabular}{|l|l|}
\hline Freak & CCVVC \\
\hline Freakking & CCVVCCVCC \\
\hline
\end{tabular}

consonant ' $\mathrm{K}$ ' in the middle of the word, added vowel in before the last word, consnan ' $\mathrm{N}$ ' before the last word and consnant ' $G$ ' in the last word -> 'freakking' and it changed CCVVC sequence became CCVVCCVCC sequence of FREAKKING. 
Sample 8:

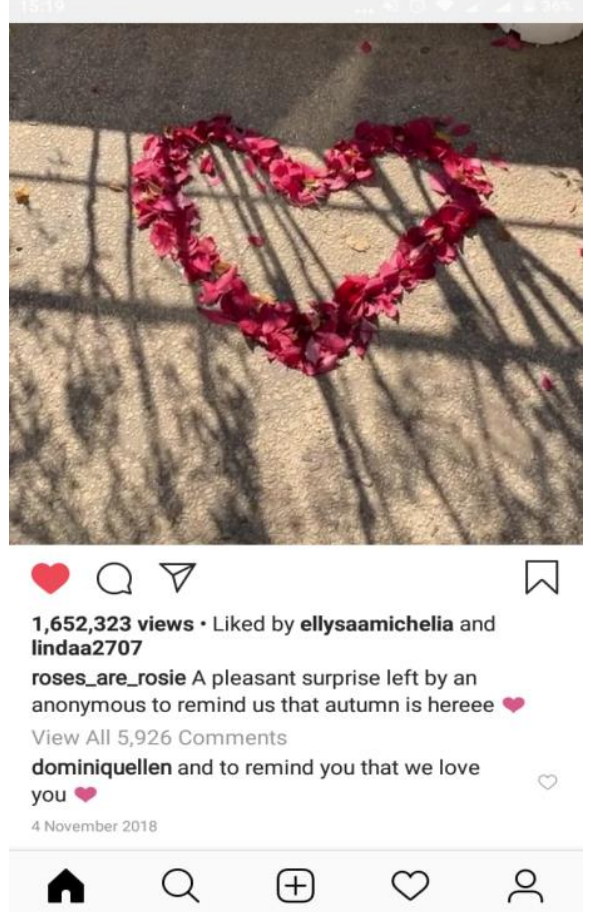

In sample 8 the data was taken on May 20, 2019 on Roses_are_rosie's statues posting on November 4, 2018. In a word 'HERE' is written to HEREE, the word 'HERE' consist of four characters, they H-E-R-E than Roses was written HEREE, she was paragoged the word 'HEREE' by vowel ' $E$ ' in the end of the word -> 'HEREE' and it changed cvcV sequence became CVCVV sequence of HEREE.

\begin{tabular}{|l|l|}
\hline Here & CVCV \\
\hline Heree & CVCVV \\
\hline
\end{tabular}

\section{CONCLUSION}

In this research the researcher found many word that was paragoged by Roses blackpink in her captions, the first is the word smile she was paragoged became smilee, second the word peace became Peaaacccee, so the word love she was paragoged became loovee, the word crazy became crraaazzy, the word freak became freaking and the las is the word here became heree, she was paragoged the word in the second word, before the last word and in the end of word. 


\section{REFERENCES}

Creswell, John. W. 1994. Research Design: Qualitative, Quantitative, and mixed methods approaches. California: Sage Publigation.

Tai, Lam Nguyen. The Morphophonemics of English

Field, John. 2003. PSYCHOLINGUISTICS A resources book for student. Newyork: Taylor and francis group

Ng, E-Ching (2013) Paragoge as an indicator of languagae contact. Yale Univers 